\title{
A Defense of Traditional Hypotheses about the Term Structure of Interest Rates
}

\section{Citation}

Campbell, John Y. 1986. A defense of traditional hypotheses about the term structure of interest rates. Journal of Finance 41(1): 183-193.

\section{Published Version}

http://dx.doi.org/10.2307/2328351

\section{Permanent link}

http://nrs.harvard.edu/urn-3:HUL.InstRepos:3207698

\section{Terms of Use}

This article was downloaded from Harvard University's DASH repository, and is made available under the terms and conditions applicable to Other Posted Material, as set forth at http:// nrs.harvard.edu/urn-3:HUL.InstRepos:dash.current.terms-of-use\#LAA

\section{Share Your Story}

The Harvard community has made this article openly available.

Please share how this access benefits you. Submit a story.

Accessibility 
HBER WORKING PAPER SERIES

\section{A DEFENSE OF TRADITIONAL HYPOTHESES ABOUT THE TERM \\ STRUCTURE OF INTEREST RATES}

John Y. Campbell

Working Paper No. 1508

\section{HATIONAL BUREAU OF ECONOMIC RESEARCH 1050 Massachusetts Avenue \\ Cambridge, MA 02138 \\ November 1984}

This paper is besed on Chapter 2 of my Yale PhD dissertation, Asset Duration and Time-Varying Risk Premia. I am grateful to J. Huston McCulloch, Kermit Schoenholtz and Robert Shiller for helpful correspondence and discussions. The research reported here is pert of the NBER'B research program in Financial Markets and Monetary Economics. Any opinions expressed are those of the author and not those of the National Bureau of Economic Research. 
NBER Working Paper \#1508

\title{
A Defense of Traditional Hypotheses \\ About the Term \\ Structure of Interest Rates
}

\begin{abstract}
Expectations theories of asset returns may be interpreted as stating either that risk premia are zero, or that they are constant through time. Under the former interpretation, different versions of the expectations theory of the term structure are inconsistent with one another, but I show that this does not necessarily carry over to the constant risk premium interpretation of the theory. Furthermore, I argue that differences among expectations theorfes are of "second order" in a precise mathematical sense. I present an approximate 1 inearized framework for analysis of the term structure in which these differences disappear, and I test its accuracy in practice using data from the CRSP government bond tapes.
\end{abstract}

John Y. Campbe11

Dept. of Economics

Dickins on $\mathrm{Hall}$

Princeton University

Princeton, NJ 08544

(609) $-452-4011$ 


\section{A DEFENSE OF TRADITIONAL HYPOTHESES ABOUT}

THE TERM STRUCTURE OF INTEREST RATES

In a well-known article, Cox, Ingersoll and Ross (CIR) [4] re-examine and find wanting certain hypotheses about the term structure of interest rates.

A striking feature of CIR's re-examination is that it is entirely theoretical. CIR show that different versions of the pure expectations theory of the term structure, which traditionally were regarded as equivalent, are in fact inconsistent with one another when interest rates are random. Furthermore, in a fairly general continuous time arbitrage pricing framework, when interest rates are random all versions of the theory except one are incompatible with equilibrium. CIR show that the single version which survives this test, the so-called Local Expectations Hypothesis, does not necessarily have the properties ascribed to it in the literature. In particular, it is not associated with risk-neutrality and it does not necessarily imply that the long rate is linear in short rates if the short rate is linear in its own past history.

At first sight $\mathrm{CIR}^{\prime} s$ results appear to be devastating to traditional empirical work on the term structure. They suggest that researchers must specify arbitrage pricing models with a swall number of state variables before proceeding to empirical work. Such models must restrict not only the deterministic components of interest rate movements, but also the variance-covariance matrix of interest rate inno- 
vations and the information set of market participants. ${ }^{2}$

The purpose of this paper is to defend traditional hypotheses about the term structure as a starting point for empirical research. Although these hypotheses may as a matter of fact be false, it is meaningful to test them against the data; useful empirical work can be done outside the confines of tightly specified arbitrage pricing models.

The defense has two parts. In the first, I argue that CIR's criticisms apply to a more restrictive type of expectations theory than is typically studied in the empirical literature. In the second, I show that the inconsistencies pointed out by CIR are of "second order" in a precise mathematical sense, and I claim that they may often be ignored in empirical work.

Section I of the paper presents the first part of the defense. I begin by showing that it is natural to express a version of an expectations theory of the term structure as a statement about the expected difference between a random variable and a known one. Such an expected difference may be called a term premium or risk premium. CIR discuss versions of the pure expectations theory of the term structure, which states that term premia are zero. ${ }^{2}$ But much of the literature is concerned with versions of a less restrictive theory, which states

1 For example, on page 790 CIR discuss a model in which the short rate follows an elastic random walk: $d r=k(m-r) d t+s(r) d z$. The model is closed by assuming that $s(r)=\operatorname{sqrt}[a+b r]$ and that $k(m-r)$ is not only the best forecast of $d r$ conditional on $r$, but also the best forecast which can be made by the market.

2 This terminology is due to Lutz [9]. 
merely that term premia are constant through time. These are referred to here as versions of the expectations theory of the term structure.

CIR's basic point is that when interest rates are random different term premia are not equivalent to one another because of Jensen's Inequality. This is, of course, correct. But it turns out that different versions of the expectations theory, as opposed to the pure expectations theory, are not necessarily incompatible with each other or with arbitrage pricing equilibrium.

In section II I argue that in any case the differences among term premia are of second order. ${ }^{3}$ I present an approximate linearized framework for the analysis of the term structure, in which these differences disappear. The framework has a number of advantages. It states a linear relationship between the level and change of a bond yield and the holding return on the bond; it can easily be applied to coupon bonds as well as to discount bonds (bills); it suggests simple regression tests of the expectations theory. In section III I briefly examine the empirical accuracy of the approximation, using data from the CRSP government bond tapes.

3 Honohan [7] also argues along these lines. He points out that arbitrage models themselves are only approximations to reality, so results based on analysis of these models should not be treated as exact . 


\section{Expectations Theories: Zero versus Constant Risk Premia}

Following $C I R, I$ define $P(Y, t, T)$ as the price at time $t$ of a claim to one dollar at time T." This price is a function of $t, T$ and some vector of state variables $Y$, which summarizes the state of the economy at time $t$. The corresponding yield to maturity is

(1) $y(Y, t, T)=-[1 /(T-t)] \ln P(Y, t, T)$

which can also be written as

(1) $P(Y, t, T)=\exp [-(T-t) y(Y, t, T)]$

The yield is that rate of continuous discount which equates the present value of the final payment to the current price. Equivalently, it is the continuously compounded rate of return on holding the claim to maturity.

At any time $t$, and for given state $Y$, the term structure of interest rates is the set of $P(Y, t, T)$ considered as a function of $T$. Assume that this function is differentiable. Then the instantaneous forward rate on a loan at time $T$, entered into at $t$ ime $t$, is

(2) $f(Y, t, T)=-[\partial P(Y, t, T) / \partial T] / P(Y, t, T)$

"This section considers only claims to a single payment - that is bills or discount bonds - and not claims to a stream of payments that is coupon bonds. Coupon bonds are discussed in the next section. 


$$
=y(Y, t, T)+(T-t)[\partial y(Y, t, T) / \partial T]
$$

To understand this definition, consider buying one claim to a dollar at $T+\Delta T$ for $P(T+\Delta T)$ and selling $P(T+\Delta T) / P(T)$ clatms to a dollar at $T$ for $P(T)$ each. This operation fncurs no costs until $T$, when $\mathrm{P}(\mathrm{T}+\Delta \mathrm{T}) / \mathrm{P}(\mathrm{T})$ dollars must be patd. One dollat is then received at $T+\Delta T$. The yield is $-\ln [P(T+\Delta T) / P(T)] / \Delta T$ which approaches $-[\partial P(T) / \partial T] / P(T)$ as $\Delta T$ approaches zero.

Equation (2) states a relation between the instantaneous forward rate and the yield which is analogous to the relation between marginal and average cost. Thus, for example, when the yield is rising with maturity the forward rate is higher than the yield.

The instantaneous spot rate of interest at time $t, r(Y, t)$, is the limit as $T$ approaches $t$ of both $f(Y, t, T)$ and $y(Y, t, T)$.

The instantaneous holding return at time $t$ on a claim maturing at $T$ is

(3) $h(Y, t, T)=d P(Y, t, T) / P(Y, t, T)$

where $\mathrm{dP}$ is the change in $\mathrm{P}$ over an interval of time dt. A1though it is reasonable to assume that the term structure is a differentiable function of maturity $T$, it is less reasonable to assume that bond prices are differentiable with respect to $t$. Following CIR, I assume that bond prices follow diffusion processes and hence are undifferentiable with respect to time if they are random. 
I am now able to define two term premia which are the primitive objects of expectations theories. The instantaneous holding premium $\phi(Y, t, T)$ is defined by

(4) $\phi(Y, t, T)=E_{t} h(Y, t, T)-r(Y, t)$

where $E_{t}$ denotes mathematical expectation conditional on the information $Y$ available at time $t$. The instantaneous forward premium $\psi(Y, t, T)$ is defined by

(5) $\psi(Y, t, T)=f(Y, t, T)-E_{t} I(Y, T)$

The instantaneous holding premium is the expected difference at $t$ between the instantaneous holding return on bond which matures at $T$ and the spot rate at $t$. The instantaneous forward premium is the expected difference at $t$ between the forward rate at $T$ and the spot rate at $\mathrm{T}$.

Equations (4) and (5) can be integrated with respect to $t$ and $T$ respectively, to give expresstons relating the price or yield of a bond to expected spot rates and premia. We obtain

(4)' $\left.P(Y, t, T)=E_{t}[\exp \underset{t}{T}[r(Y, s)+\phi(Y, s, T)] d s)\right]$

(5)' $\quad-\ln P(Y, t, T)=(T-t) y(Y, t, T)$ 


$$
=\int_{t}^{T}\left[E_{t} r(Y, s)+\psi(Y, t, s)\right] d s
$$

CIR also discuss a third type of premium. This is defined as the difference between the gross, uncompounded return on holding a bond to maturity and the expected equivalent return on receiving the spot rate at each instant of time:

$\left.\phi^{*}(Y, t, T)=[1 / P(Y, t, T)]-E_{t} l \exp \int_{t}^{T} r(Y, s) d s\right]$

I do not discuss this premium concept further here, as it seems more natural to consider a rate of return over an interval of time in the manner of equation (1).

Having defined $\phi(Y, t, T)$ and $\psi(Y, t, T)$, it is trivial to state two versions of the pure expectations theory considered by CIR: these are $\phi(Y, t, T)=0$ for all $Y, t$ and $T$ (CIR's "Local Expectations Hypothesis") and $\psi(Y, t, T)=0$ for all $Y, t$ and $T$ (CIR's "Yield to Maturity Expectations Hypothesis"). Under the pure expectations theory, holding or forward premia are zero.

It is also trivial to state the corresponding versions of the expectations theory: $\phi(Y, t, T)=H(T-t)$ and $\psi(Y, t, T)=F(T-t)$. Under the expectations theory, holding or forward premia are constant through time after controlling for maturity.

CIR show that the theories $\phi=0$ and $\psi=0$ are inconsistent when interest rates are random, by applying Jensen's Inequality to equa- 
tions (4)' and (5)'. Further, they use an arbitrage argument to show that the theory $\psi=0$ is incompatible with any rational expectations equilibrium. The following theorem demonstrates that these results do not carry over to the theories $\phi(Y, t, T)=H(T-t)$ and $\psi(Y, t, T)=$ $F(T-t)$.

Theorem. Under CIR's notation and assumptions A.1 through A.7, if $\lambda(Y, t)=\lambda$ and $\delta(Y, t, T)=\delta(T-t)$, then there exist functions $H(T-t)$ and $F(T-t)$ such that $\phi(Y, t, T)=H(T-t)$ and $\psi(Y, t, T)=F(T-t)$.

Interpretation. CIR's assumptions A.1 through A.7 establish the conditions for an arbitrage pricing argument. Assumptions A.1 and A.2 postulate that the state of the economy is sumarized by $\mathrm{N}$ state variables in the $\mathrm{N}$-vector $\mathrm{Y}$, driven by $\mathrm{K}$ underlying sources of uncertainty (Wiener processes). The subsequent arbitrage pricing argument requires at least $K$ bonds to be traded. A.3 places very mild restrictions on investors' preferences, and A.4 through A.7 describe asset markets as perfect and frictionless.

In CIR's notation, $\delta(Y, t, T)$ is a K-vector describing the sensitivity of the return on a bond maturing at $T$, in state $Y$ at time $t$, to the $K$ sources of uncertainty. $\lambda(Y, t)$ is a K-vector describing the market price of each of the $K$ sources of uncertainty. The conditions of the theorem are that market risk prices are constant, and that the sensitivities of bond returns to each source of risk are functions only of bond maturity and not of time or the state of the economy. Then it is unsurprising that term premia should be functions only of maturity. 
The theorem shows by example that the theory $\psi=F(T-t)$ is compatible with equilibrium, and is not necessarily inconsistent with the theory $=H(T-t)$. It might be possible to construct examples in which $=\mathrm{H}(\mathrm{T}-\mathrm{t})$ but $\psi \neq F(\mathrm{~T}-\mathrm{t})$ or vice versa. However the example given seems to be the most natural way for $=H(T-t)$ or $\psi=F(T-t)$ to arise.

Proof. Assumptions A.1 through A.7 imply that holding returns on all bonds can be written as

(6) $h(Y, t, T)=\alpha(Y, t, T) d t+\delta^{\prime}(Y, t, T) d z(t)$

- where $\alpha$ is the expected instantaneous return and $z(t)$ is the $K$-dimensional standardized Wiener process driving the economy. An arbitrage argument shows that

(7) $\alpha(Y, t, T)=I(Y, t)+\lambda^{\prime}(Y, t) \delta(Y, t, T)$

Substituting (7) into (6), taking expectations and using the definition of $\phi(Y, t, T)$, we have

(B) $\phi(Y, t, T)=\lambda^{\prime}(Y, t) \delta(Y, t, T)$

But if $\lambda(Y, t)=\lambda$ and $\delta(Y, t, T)=\delta(T-t)$ then

(B) $\phi(Y, t, T)=\lambda^{\prime} \delta(T-t)=H(T-t)$ 
Next we check to see whether $\psi(Y, t, T)=F(T-t)$ in this case. If this theory holds, then equation (5)' can be written as

$$
\begin{aligned}
& (5)^{\prime \prime}-\ln P(Y, t, T)=(T-t) y(Y, t, T) \\
& =\int_{t}^{T}\left[E_{t} r(Y, s)+F(s-t)\right] d s
\end{aligned}
$$

It follows that

(9) $E_{t}[d \ln (P)]=r(t)+F(T-t)$

But by Ito's lemma,

(10) $d \ln (P)=\left(\alpha-\delta^{\prime} \delta / 2\right) d t+\delta^{\prime} d z$

so combining (9) and (10) we have

(11) $\alpha(Y, t, T)-\delta^{\prime}(T-t) \delta(T-t) / 2=I(Y, t)+F(T-t)$

But $\alpha(Y, t, T)-r(Y, t)=H(T-t)$ so we have

(12) $\quad F(T-t)=H(T-t)-\delta^{\prime}(T-t) \delta(T-t) / 2$

$$
=\left[\lambda^{\prime}-\delta^{\prime}(T-t) / 2\right] \delta(T-t)
$$


Thus we have found a solution for $F(T-t)$ and verified that the theory $\psi=F(T-t)$ holds under the conditions of the theorem.

Comment. The third type of premium discussed by CIR is not constant under the conditions of the theorem. It is easy to show that this premium is proportional to the expected uncompounded gross return on receiving the spot rate at each instant of time,

$$
\phi *(Y, t, T)=G(T-t) E_{t}\left[\exp \int_{t}^{T} r(Y, s) d s\right]
$$


II. An Approximate Linearized Framework for Study

of the Term Structure

In this section I present a set of linear approximations relating forward rates, holding returns and yields to maturity. These approximations serve a double purpose. First, they show that the inconsistencies pointed out by Cox, Ingersoll and Ross are of second order in a precise mathematical sense. Secondly, they can be derived for coupon bonds as well as discount bonds, and thus allow an easy direct approach to the study of coupon bond data. 5

The first step is to derive a coupon bond equivalent of equation (2). Define the yield to maturity on a coupon bond which pays a continuous coupon stream at rate $C$ from $t$ to $T$, and then a final payment of a dollar at time $T$, by the implicit function

$$
\begin{aligned}
& C \int_{t}^{T} \exp \left[-(s-t) y_{C}(Y, t, T)\right] d s+\exp \left[-(T-t) y_{C}(Y, t, T)\right] \\
& =P_{C}(Y, t, T)=C \int_{t}^{T} P(Y, t, s) d s+P(Y, t, T)
\end{aligned}
$$

This equation states that $y_{C}(Y, t, T)$ is that rate of return which discounts the coupon and principal payments of the bond to $P_{C}(Y, t, T)$, its time $t$ price." The price is just the sum of those payments' present

5 Traditionally, researchers have followed McCulloch [12] and transformed a coupon bond yield curve into an implied discount bond yield curve before conducting their analysis. This procedure is elaborate and itself subject to error.

- Note that when ${ }^{P_{C}}=1$ (the bond is selling at par), the yield just 
values - a coupon bond is equivalent to a portfollo of discount bonds - so $P_{C}(Y, t, T)$ can also be written in terms of discount bond prices $P(Y, t, T)$ or discount bond yields $y(Y, t, T)$.

Equation (13) expresses a complicated nonlinear relationship between $y_{C}, C$ and the term structure of discount bond yields $\{y(Y, t, s)\}$.

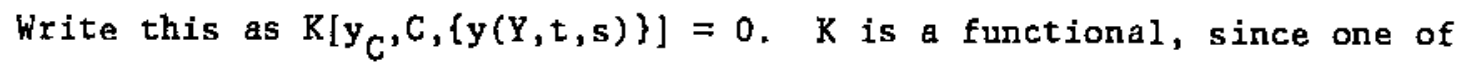
its arguments is $\{y(Y, t, s)\}$, a function of $s$. The first-order expansion of $\mathrm{K}$ is obtained by applying the calculus of variations, in a manner analogous to the Taylor expansion for a function. Expanding about the path $y_{C}=C=\{y(Y, t, s)\}=R$ for some $R$, we obtain

(14) $K\left[y_{C}, C,\{y(Y, t, s)\}\right] \simeq K[R, R,\{R\}]$

$$
+\left(y_{C}-R\right) \partial K / \partial y_{C}+(C-R) \partial K / \partial C+\varepsilon \partial K / \partial \varepsilon
$$

where the derivatives are evaluated at the point $\{R, R,\{R\}\}$ and $\varepsilon$ is defined by $y(Y, t, s)=R+\varepsilon \xi(Y, t, s) . \xi(Y, t, s)$ is the "variation" in the path of zero-coupon rates; to obtain the solution $I$ set $\xi(Y, t, s)=$ $y(Y, t, s)-R$ and $\varepsilon=1$. Details of the linearization procedure are explained in the Appendix to this paper.

Equation (14) generates a simple linear approximate relationship between $y_{C}(Y, t, T)$ and the term structure of forward rates $\{f(Y, t, s)\}$. $C$ does not appear in this relation. We have

$$
y_{C}(Y, t, T)=[R /(1-\exp [-(T-t) R])] \int_{t}^{T} \exp [-R(s-t)] f(Y, t, s) d s
$$

equals the coupon rate $C$. 
This can be rearranged to express the forward rate $f(Y, t, T)$ as a function only of the level and slope of the term structure of coupon bond yields at the point $(t, T)$ :

$$
\begin{aligned}
f(Y, t, T) & =y_{C}(Y, t, T) \\
+ & {[1-\exp [-(T-t) R]] /[R(\exp [-(T-t) R])] \partial y_{C}(Y, t, T) / \partial T }
\end{aligned}
$$

These equations can be interpreted in a more intuitive way, and related more closely to equation (2), by introducing the concept of "duration". Duration was defined by Macaulay [10] as the present-va1ue-weighted average length of time before repayment of a loan, where the yield to maturity on the loan is used to compute present value. ${ }^{7}$ The duration $D_{C}\left(y_{C}, t, T\right)$ of a bond maturing at $T$ with coupon $C$ and yield $y_{C}$ is

$$
D_{C}\left(y_{C}, t, T\right)=C \int_{t}^{T}(s-t) \exp \left[-(s-t) y_{C}\right] d s+(T-t) \exp \left[-(T-t) y_{C}\right]
$$

At the point of linearization, the duration is

$$
\begin{aligned}
(17)^{\prime} D_{R}(T-t) & =R \int_{t}^{T}(s-t) \exp [-(s-t) R] d s+(T-t) \exp [-(T-t) R] \\
& =[1-\exp [-(T-t) R] / R
\end{aligned}
$$

7 Macaulay also mentions that the true discount function could be used to compute present value. These two definitions are equivalent at the point of linearization. 
It follows that $\partial D_{R}(T-t) / \partial T=\exp [-(T-t) R]$, and we can rewrite (15) and (16) as

$(15)^{\prime} y_{C}(Y, t, T) \approx\left[1 / D_{R}(T-t)\right] \int_{t}^{T} \partial D_{R}(s-t) / \partial s f(Y, t, s) d s$

(16)' $f(Y, t, T)=y_{C}(Y, t, T)+\left[D_{R}(T-t) /\left(\partial D_{R}(T-t) / \partial T\right)\right] \partial y_{C}(Y, t, T) / \partial T$

Equation (16)' is directly analogous to equation (2), expressing a marginal-average relation between the forward rate and the coupon bond yield. The concept of duration also applies to discount bonds, for which $D_{R}(T-t)=(T-t)$ and $a D / a T=1$. Then equation $(16)^{\prime}$ reduces to equation (2) and holds exactly.

Next I apply the method of linear approximation to the holding return on a coupon bond. In a straightforward modification of equation (3), this holding return is defined as

(18) $h_{C}(Y, t, T)=\left[d_{C}(Y, t, T)+C d t\right] / P_{C}(Y, t, T)$

A coupon bond yields a direct return from its coupon payment even if there is no capital gain $\mathrm{dP}_{\mathrm{C}}$.

Recall that $P_{C}$ is a function of $y_{C}$ and $C$ : from equation (13),

$P_{C}=\left(C / y_{C}\right)\left[1-\exp \left[-(T-t) y_{C}\right]\right]+\exp \left[-(T-t) y_{C}\right]$ 
I now assume that the coupon bond yield $y_{C}$ follows an Ito process' with parameters $\mu$ and $\sigma$ :

$$
d y_{C}(Y, t, T)=\mu(Y, t, T) d t+\sigma(Y, t, T) d z
$$

Now I can apply Ito's lemma to (18), and obtain

$$
\begin{aligned}
h_{C} & =\left\{\left[\partial P_{C} / \partial y_{C}\right] d y_{C}+\left[C+\partial P_{C} / \partial t+\left(\partial^{2} P_{C} / \partial y_{C}{ }^{2}\right) \sigma^{2} / 2\right] d t\right\} / P_{C} \\
& =\left\{\left[\partial P_{C} / \partial y_{C}\right] d y_{C}+\left[y_{C} P_{C}+\left(\partial^{2} P_{C} / \partial y_{C}{ }^{2}\right) \sigma^{2} / 2\right] d t\right\} / P_{C}
\end{aligned}
$$

where the second step uses the fact that $\mathrm{y}_{\mathrm{C}} \mathrm{P}_{\mathrm{C}}=\mathrm{C}+{ } \mathrm{P}_{\mathrm{C}} / \partial \mathrm{t}$. The intuition here is that when $\mu=\sigma=0, h_{C}=y_{C}(Y, t, T) d t$ : the rate of holding return is just the yield. Some of this return comes from price change, which makes up the difference between the yield and the coupon return: if the yield is higher than the coupon, the bond sells for less than par and appreciates towards par as it nears maturity. When $\sigma>0$ the expected holding return exceeds the yield even when $\mu=0$ and there is no expected change in the yield. However, we shall see that this effect is of "second order" in that it does not appear in the linearized holding return.

8 This assumption is perfectly consistent with the assumption of CIR that the bond price follows an Ito process with parameters $\alpha P$ and $\delta P$ (equation (6)). Equation (10) expresses the yield on a discount bond as an Ito process, and gives the parameters of this process as functions of $a$ and $\delta$. An equivalent solution for the yield on a coupon bond cannot be calculated explicitly, but it will have the form stated in the text. 
point $\mathrm{C}=\mathrm{y}_{\mathrm{C}}=\mathrm{R}, \mu=\sigma=0$ :

$$
\begin{aligned}
h_{C}=R d t & +(C-R) \partial h_{C} / \partial C+\left(y_{C}-R\right) \partial h_{C} / \partial y_{C} \\
& +\mu \partial h_{C} / \partial \mu+\sigma \partial h_{C} / \partial \sigma
\end{aligned}
$$

The details of the calculation are given in the Appendix to this paper: the linear approximation which results is

$$
h_{C}(Y, t, T) \simeq y_{C}(Y, t, T) d t-D_{R}(T-t) d y_{C}(Y, t, T)
$$

Equation (21) says that, ceteris paribus, a high bond yield means a high instantaneous holding return. However, an increase in the yield causes a capital loss proportional to the duration of the bond, and lowers the holding return accordingly.

The proportional relationship between duration and the response of holding return to yield is easier to understand when one notes that duration as defined in equation (17) is just $\left(-1 / y_{C}\right)$ times the elasticity of ${ }^{P_{C}}$ with respect to $y_{C}$. Duration is constructed to measure the response of price, and therefore holding return, to changes in yield.

Equation (22) can be used to express the yield on a coupon bond as a function of future holding returns. We have, by construction of $D_{R}(T-t)$, 
(23) $y_{C}(Y, t, T)=\left(1 / D_{R}(T-t)\right) \int_{t}^{T} \partial D_{R}(s-t) / \partial s\left[y_{C}(Y, s, T)-D_{R}(T-s) \mu(s, T)\right] d s$

$$
+\left(1 / D_{R}(T-t)\right) \int_{t}^{J} \quad \partial D_{R}(s-t) / \partial s\left[D_{R}(T-s) \sigma(s, T)\right] d z(s)
$$

Substituting equation (19) into equation (22), we can simplify equation (23):

(23)' $\mathrm{y}_{\mathrm{C}}(\mathrm{Y}, \mathrm{t}, \mathrm{T}) \simeq\left(1 / \mathrm{D}_{\mathrm{R}}(\mathrm{T}-\mathrm{t})\right) \begin{aligned} & \mathrm{T} \\ & \mathrm{f}\end{aligned} \quad \partial \mathrm{D}_{\mathrm{R}}(\mathrm{s}-\mathrm{t}) / \partial \mathrm{s}_{\mathrm{C}}(\mathrm{Y}, \mathrm{s}, \mathrm{T}) \mathrm{ds}$

The coupon bond yield is an approximate weighted sum of future holding returns. Note that this equation holds in realization, and not just in expectation.

Equations (15)' and (16)', and (22) and (23)', make up a complete linearized framework for analysis of the term structure. It is easy to see that within this framework there are no inconsistencies between expectations theories. Taking expectations of (23)', substituting equations (5) and (4) into (15)' and (23)', and equating the right hand sides of (15)' and (23)', we have

$$
\begin{aligned}
& \left(1 / D_{R}(T-t)\right) \int_{t}^{T}\left(\partial D_{R}(s-t) / \partial s\right) \psi(Y, t, s) d s \\
& \simeq\left(1 / D_{R}(T-t)\right) \int_{t}^{T}\left(\partial D_{R}(s-t) / \partial s\right) \phi(Y, s, T) d s
\end{aligned}
$$


Within the linearized system, if $\phi(Y, t, T)=0$ for all $Y, t$ and $T$, then $\psi(Y, t, T)=0$ for $a l 1 Y, t$ and $T$ : these two forms of the pure expectations theory imply one another. A fortiori, the corresponding forms of the expectations theory imply each other.

The linearized system also suggests a simple test of the expectations theory. Taking expectations of equation (22), and substituting in equation (4), we have

$$
\begin{aligned}
E_{t} d y_{C}(Y, t, T)= & \left(1 / D_{R}(T-t)\right)\left[y_{C}(Y, t, T)-r(Y, t)\right] \\
& +\left(1 / D_{R}(T-t)\right) \phi(Y, t, T)
\end{aligned}
$$

Under the pure expectations theory the second term on the right hand side of (25) is zero, while under the expectations theory it is constant. (25) states that when the long rate $y_{C}$ is (unusually far) above the short rate $r$, the long rate is expected to rise. This causes an expected capital loss which offsets the higher yield on long bonds. (25) can be tested by regressing the change in the long rate on the long-short spread, and testing for equality of the estimated coefficient with $\left(1 / D_{R}(T-t)\right)$. This was the approach of Shiller, Campbe11 and Schoenholtz [13], who derived a discrete-time equivalent of the linearized system of this paper, and of Mankiw and Summers [11].

A closely related test is to regress realized excess returns on long bonds, $h_{C}-r$, on the long-short spread $y_{C}-r$. Under the expectations hypothesis, no variable known in advance predicts $\mathrm{h}_{\mathrm{C}}$-r beyond a constant term; but under the alternative of a time-varying risk premi- 
um, proxies for $\phi$ should predict $h_{C}-r$. Equation (25) shows why the spread is a good proxy. It states that $y_{C}-r=\phi+D_{R} E_{t} d y_{C}$, so if expected changes in long rates vary little, the spread moves close to one for one with the risk premium. Campbell and Shiller 13], Fama [5] and Huizinga and Mishkin [8] have conducted tests of this sort.

One final implication of equation (25) with a constant risk premium is that long and short rates are "co-integrated" in the sense of Granger [6]. That is, if long rates follow an ARIMA process of integrated order d, then the long-short spread, being related to the expected change in long rates, is integrated of order (d-1). Furthermore the long rate is linear in current and lagged short rates if the short rate is linear in lagged short rates. The linearized system lends itself to time series analysis of interest rates, as in Campbe11 [2]. 


\section{The Accuracy of the Linearized Framework}

In this section $I$ present some tests of the empirical accuracy of the linear approximations of this paper. I focus on the approximate expression for the holding return on a long bond.9

In section 2 an approximation was derived only for the instantaneous holding return. This is easily extended to the return on holding $a$ bond from time $t$ to time $t^{\prime}, h_{C}\left(Y, t, t^{\prime}, T\right)$ :

$$
h_{C}\left(Y, t, t^{\prime}, T\right)=\left(1 / D_{R}\left(t^{\prime}-t\right)\right) \int_{t}^{T} \partial D_{R}(s-t) / \partial s h_{C}(Y, s, T) d s
$$

This equation is analogous to the expression (23)' for the yield on a coupon bond: but here the integral runs from to $t$ ' rather than from $t$ to $T$. It follows from $(23)^{t}$ and (26) that the yield on a bond maturing at $\mathrm{T}$ can be expressed as an approximate weighted sum of period holding returns :

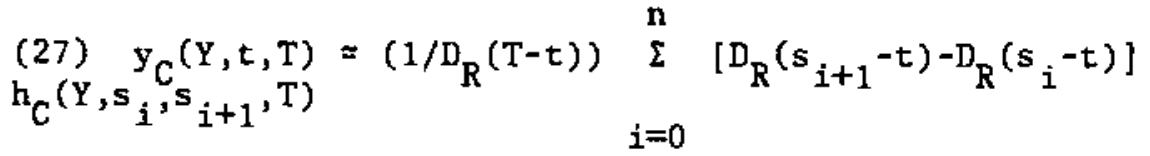

where $t=s_{0}<s_{1}<\ldots<s_{n}=T$. Also the period holding return is a simple linear function of the yields at times $t$ and $t^{\prime}$ on a bond maturing at time $\mathrm{T}$ :

- Berger [1] examined a similar approximation for returns on consols; his test assumed that 20 and 30 year government bonds are effectively consols. Shiller, Campbell and Schoenholtz [13] tested an approximation for forward rates. 


$$
\left[D_{R}(T-t) y_{C}(Y, t, T)-\left(D_{R}(T-t)-D_{R}\left(t^{\prime}-t\right)\right) y_{C}\left(Y, t^{\prime}, T\right)\right] / D_{R}\left(t^{\prime}-t\right)
$$

In the empirical work of this section I use the discrete time version of (28), developed by Shiller, Campbell and Schoenholtz [13], in which

$$
D_{R}(s-t)=\left(1-\gamma^{s-t}\right) /(1-\gamma) \text { and } \gamma=1 /(1+R) \text {. }
$$

The Center for Research in Securities Prices (CRSP) at the University of Chicago has a complete set of monthly data on individual government bonds from 1925. This offers an opportunity to evaluate the linear approximation (28) because the data set contains both yields and exact monthly holding returns on long bonds.

In Tab1es I and II I present summary statistics for exact holding returns and two different approximate holding returns on 24 bonds. Table I covers 8 10-year bonds and 4 20-year bonds, while Table II covers 12 bonds of at least 30 years maturity at issue. A11 summary statistics are for the first 5 years (60 observations) after the bond was issued.

The two approximations in the tables, (1) and (2), differ only in the point of linearization. Approximation (1) takes the own coupon rate on the bond as the linearization point, while approximation (2) uses a common linearization point of $5.5 \%$ for all bonds. $5.5 \%$ was 
chosen because it is close to the average coupon rate of all bonds in Table II, and to the average long bond rate in the 1959-79 period. Shiller, Campbell and Schoenholtz [13] and Campbell and Shiller [3] linearized around similar points.

Three summary statistics are presented for each approximation. These are the mean error, the mean difference between the approximate holding return and the exact holding return; the correlation between the approximate and exact holding returns; and the ratio of the variance of the approximation error to the variance of the exact holding return.

The summary statistics of Tables I and II indicate that the linear approximations of this paper are reliable if used judiciously. Consider first the 10 -year bonds in rows 1 through 8 of Table I. One would expect that the approximation (1) performs well so long as the interest rate remains close to its level at the issue date. The approximation (2) should perform well if in addition the bond coupon rate is fairly close to $5.5 \%$. In rows 1 through 8 of Table I the worst mean error is in row 8 , for a bond with an $8 \%$ coupon in the period 1976:8 to $1981: 7.8 \%$ is further from $5.5 \%$ than any other coupon rate in the table, and the period was one of rapidly rising and volatile interest rates. The other mean errors never exceed absolute values of $0.196 \%$ for approximation (1) and $0.073 \%$ for approximation (2).

The correlations of exact and approximate holding returns are extraordinarily high. They exceed 0.999 for all 10-year bonds except 
row 8 , where the correlations are 0.9987 for both approximations. The ratio of the error variance to the variance of the true return is very low, never exceeding 0.003 for (1) or 0.007 for (2) except in row 8, where the ratios are 0.008 and 0.027 .

When we examine the 4 20-year bonds in rows 9 through 12 of Table I, we see a similar pattern. The correlations and mean errors are comparable to those in the first part of Table I. For bond 12, the error variance ratio reaches 0.015 for approximation (1) and 0.076 for approximation (2), but all other statistics are favorable.

In Table II, the first 7 bonds were issued with low coupons in the relatively stable 1950's and 1960's; the last 5 bonds were issued with high coupons in the turbulent 1970's. The summary statistics reflect this distinction. The first 7 rows are comparable to those of Table $I$, but in the last 5 rows the linear approximations begin to break down. There are high mean errors, reaching $3.366 \%$ for (1) and $6.174 \%$ for (2) in row 9. The correlations remain very high, falling just below 0.995 in only one case, but the error variance ratios rise to more than $10 \%$ for approximation (1) and more than $50 \%$ for approximation (2).

In conclusion, linear approximations should be used with caution in describing the period of high and volatile interest rates in the late 1970's and 1980's, and in studying extremely long-term bonds. Even here, however, the high correlations of Table II show that the approximations capture the movements of returns well. The approximations (1) and (2) behave like the exact returns, but amplified and 
damped respectively. For periods with less extreme interest rate movements, and for somewhat shorter bond maturitles, the approximations are extremely accurate. 


\section{Conclusions}

In this paper I have tried to rehabilitate a unified view of the expectations theory of the term structure. It is true that Jensen's Inequality places a wedge between different concepts of risk premia in the term structure; but under plausible circumstances, if holding period risk premia are constant this wedge is constant also. Furthermore the differences among risk premia disappear in a framework of linear approximations to term structure concepts. These approximations track monthly movements in bond returns quite accurately in postwar U.S. data. 
Appendix: Linearlzing a Continuous Time Model by Calculus of Variations

To obtain a linearized expression relating yields and forward rates, we start from equation (13) in the text, which states that

$\left(C / y_{C}\right)\left[1-\exp \left[-(T-t) y_{C}\right]\right]+\exp \left[-(T-t) y_{C}\right]=P_{C}$

$=C \int_{t}^{T} P(Y, t, s) d s+P(Y, t, T)$

The first step is to rewrite the right hand side of this expression as a function of $y(Y, t, s)$, in a form suitable for linearization by calculus of variations :

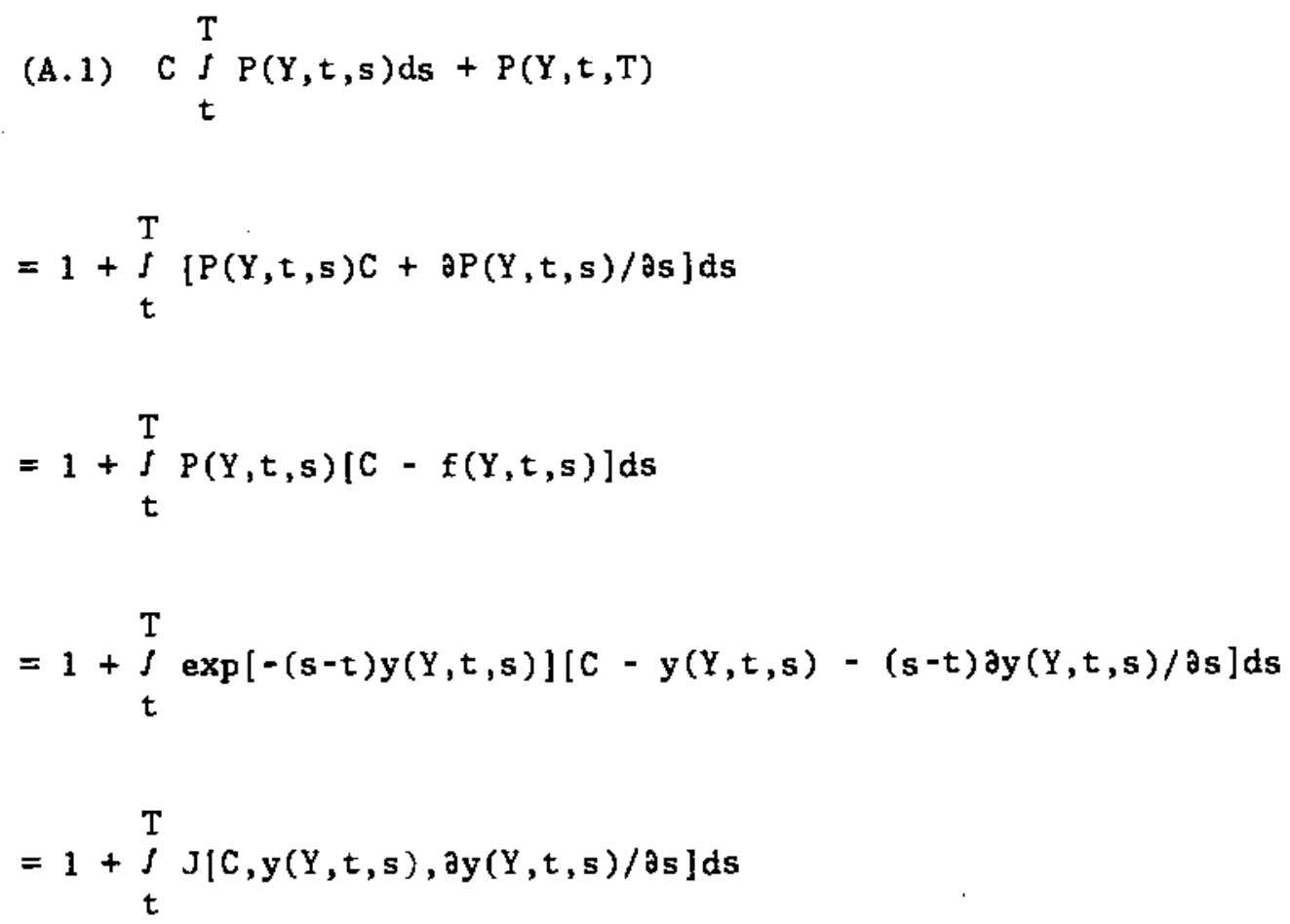


Thus we have

(A.2) $K\left[y_{C}, C,\{y(Y, t, s)\}\right]=0$

$=\left(C / y_{C}\right)\left[1-\exp \left[-(T-t) y_{C}\right]\right]+\exp \left[-(T-t) y_{C}\right]$

$-1-\int_{t}^{T} J[C, y(Y, t, s), \partial y(Y, t, s) / \partial s] d s$

The partial derivatives of $K$ with respect to its first two arguments are as follows at the point of linearization: $\partial K / \partial C=0$, and $\partial K / \partial y_{C}=$ $(1-\exp [-(T-t) R]) / R$. To evaluate $\partial K / \partial \varepsilon$, I use the calculus of variations:

(A.3) $\partial K / \partial \varepsilon=\int_{t}^{T}[(\partial J / \partial y)(\partial y / \partial \varepsilon)+(\partial J / \partial[\partial y / \partial s])(\partial[\partial y / \partial s] / \partial \varepsilon)] d s$

At the point of linearization,

(A.4) $\partial K / \partial \varepsilon=\int_{t}^{T} \exp [-(s-t) R][f(Y, t, s)-R] d s$

Substituting the derivatives into equation (14) in the text yields equation (15).

Linearization of holding returns is somewhat easier since we have an explicit formula for holding returns in equation (20) of the text. Evaluating the derivatives in equation (21), $\partial \mathrm{h}_{\mathrm{C}} / \mathrm{aC}=0$ and $\partial \mathrm{h}_{\mathrm{C}} / \partial \mathrm{y}_{\mathrm{C}}=$ dt. (This follows immediately from the observation that $h_{C}=y_{C} d t$ 
when $\mu=0=0) . \quad \partial h_{C} / \partial \mu=\left(\partial P_{C} / \partial y_{C}\right) d t / P_{C}=-d t / D_{R}(T-t)$ at the 1 inearization point. Finally, $\partial \mathrm{h}_{\mathrm{C}} / \partial \sigma=\left\{\left(\partial \mathrm{P}_{\mathrm{C}} / \partial \mathrm{y}_{\mathrm{C}}\right) \mathrm{dz}+\left(\partial^{2} \mathrm{P}_{\mathrm{C}} / \partial \mathrm{y}^{2}\right) \sigma \mathrm{dt}\right\} / \mathrm{P}_{\mathrm{C}}=$ $-d z / D_{R}(T-t)$ at the linearization point. Substituting into equation (21) yields equation (22) in the text. 
[1] Berger, Allen N., "The Exact Term Structure of Interest Rates Using Coupon Bond Data", Chapter 3 of $\mathrm{PhD}$ dissertation, Univer * sity of Calfornia at Berkeley, 1981.

[2] Campbe11, John Y., Asset Duration and Time-Varying Risk Premia, PhD dissertation, Yale University, 1984.

[3] Campbell, John Y. and Robert J. Shiller, "A Simple Account of the Behavior of Long-Term Interest Rates", American Economic Review Vo1. 74 No. 2 Papers and Proceedings pp. 44-48, May 1984.

[4] Cox, John C., Jonathan E. Ingersoll Jr. and Stephen A. Ross, "A Re-examination of Traditional Hypotheses about the Term Structure of Interest Rates", Journal of Finance Vol. 36 No. 4 pp. 769-799, 1981.

[5] Fama, Eugene F., "The Information in the Term Structure", CRSP Working Paper No. 111, Graduate School of Business, University of Chicago, March 1984.

[6] Granger, Clive W.J., "Co-Integrated Variables and ErrorCorrecting Models", Working Paper 83-13, University of California at San Diego, 1983.

[7] Honohan, Patrick, "On Some Strong Results Concerning the Term Structure", Working Paper 83-18, University of California at San Dfego, 1983. 
[8] Huizinga, John and Frederic S. Mishkin, "The Measurement of Ex-Ante Real Interest Rates on Assets with Different Risk Characteristics", unpublished paper, 1984.

[9] Lutz, Frederick A., "The Structure of Interest Rates", Quarterly Journal of Economics Vol. 55 pp. 636-663, November 1940.

[10] Macaulay, Frederick, Some Theoretical Problems Suggested by the Movements of Interest Rates, Stock Prices and Bond Yields in the United States Since 1856, National Bureau of Economic Research, New York, 1938.

[11] Mankiw, N. Gregory and Lawrence H. Summers, "Do Long-Term Interest Rates Overreact to Short-Term Interest Rates?", Brookings Papers on Economic Activity 1984:1 pp. 223-242, 1984.

[12] McCulloch, J. Huston, "Measuring the Term Structure of Interest Rates", Journal of Business Vol. 44 pp. 19-31, January 1971.

[13] Shiller, Robert J., John Y, Campbell and Kermit L. Schoenholtz, "Forward Rates and Future Policy: Interpreting the Term Structure of Interest Rates", Brookings Papers on Economic Activity 1983:1 pp. $173-217,1983$. 


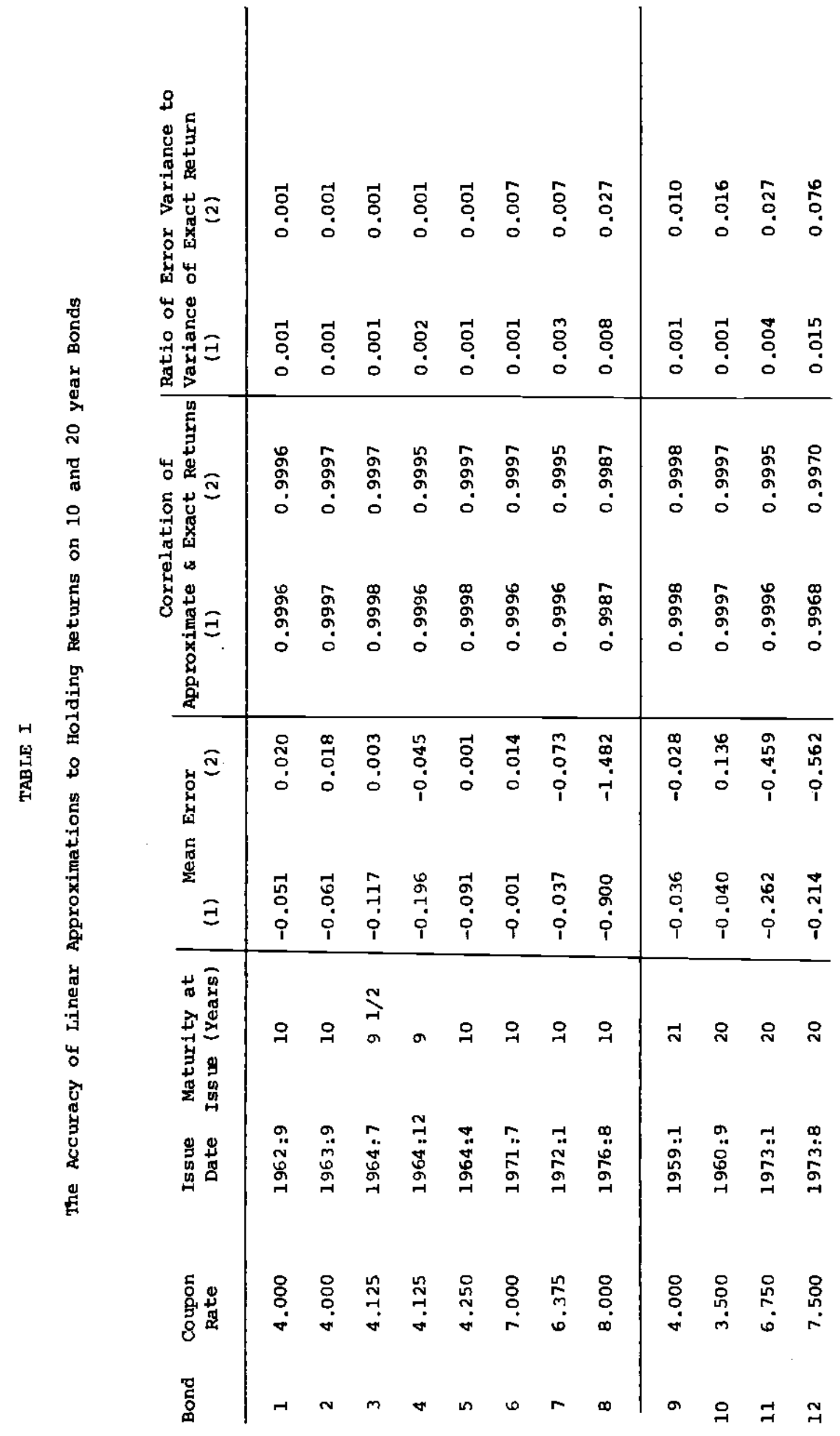




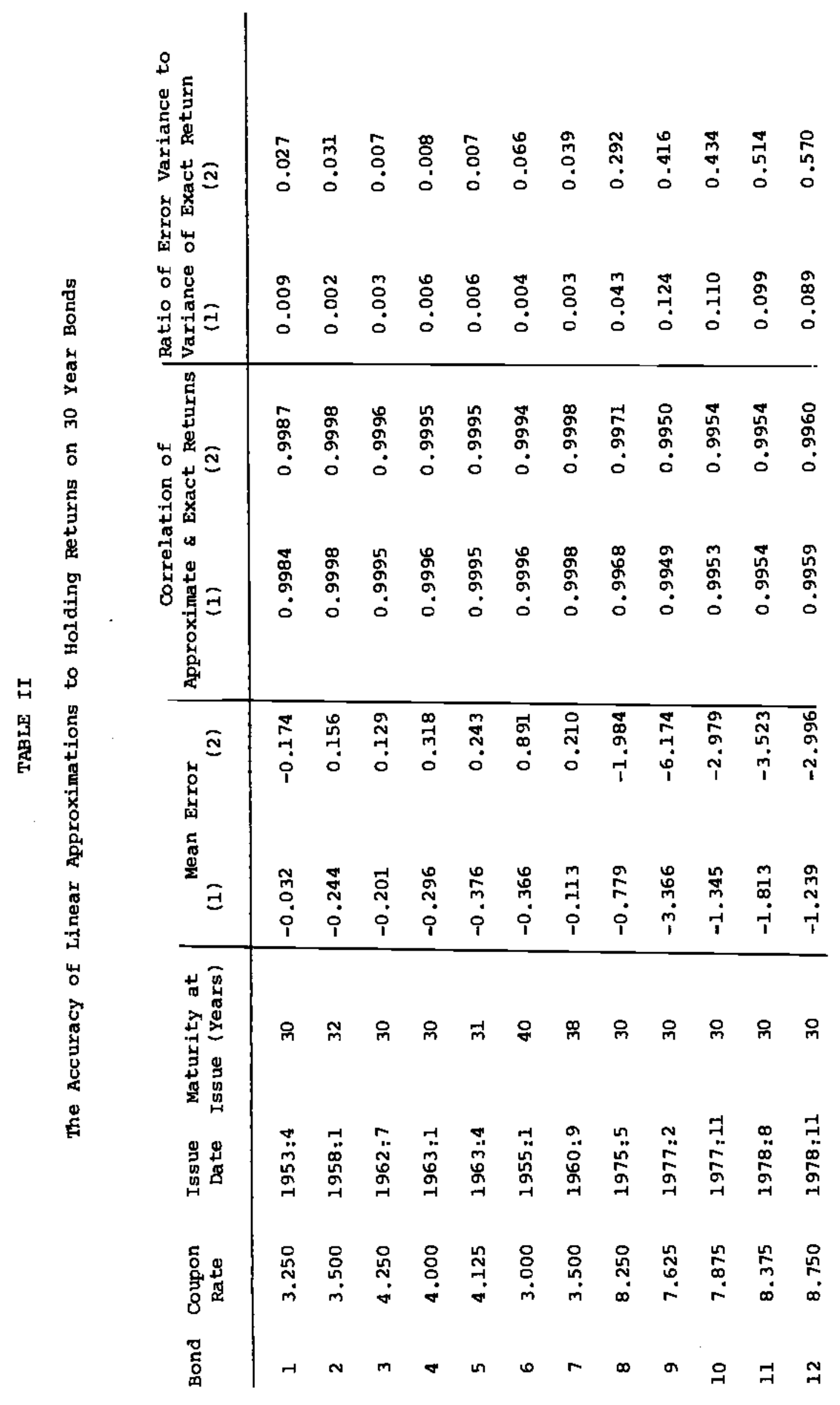

